\title{
Verifikasi Data Kemiskinan Secara Swadaya: Studi Kasus Desa Karangwangi, Kecamatan Binong, Kabupaten Subang, Jawa Barat
}

\author{
ABDUl KUdUS ${ }^{1}$, NuSAR HAJARISMAN ${ }^{2}$, TETI SOFIA YANTI ${ }^{3}$, M. YUSUF FAJAR ${ }^{4}$, \\ GANI GUNAWAN 5 \\ 1,2,3Program Studi Statistika, Fakultas MIPA, Universitas Islam Bandung \\ 4,5Program Studi Matematika, Fakultas MIPA, Universitas Islam Bandung \\ Email: abdul.kudus@unisba.ac.id
}

\begin{abstract}
ABSTRAK
Tingkat kemiskinan di Kabupaten Subang sebesar 12\%. Pendataan dilakukan oleh BPS dengan cara pengambilan sampel per blok. Terdapat banyak kasus ketidakpuasan di masyarakat mengenai data kemiskinan ini, sehingga mengganggu perencanaan dan pelaksanaan program. Berdasarkan hal tersebut maka akan sangat baik jika masyarakat merekam data sendiri berdasarkan keadaan yang sebenarnya. Dalam artikel ini dilakukan penyusunan data kemiskinan tingkat Desa Karangwangi, Kecamatan Binong, Kabupaten Subang, Jawa Barat langsung oleh masyarakat dengan pendampingan dari pihak akademisi. Tujuannya yaitu agar tercipta data kemiskinan yang akurat, timbulnya rasa empati dan saling membantu dan ketercapaian pengentasan kemiskinan melalui swadaya masyarakat. Metode yang digunakan adalah pelatihan, pendampingan, dan implementasi. Pendataan rumah tangga miskin difokuskan pada Daftar Penerima Manfaat (DPM) beras sejahtera yang dikeluarkan oleh pemerintah. Terdapat 370 rumah tangga yang termasuk dalam daftar ini. Dari daftar tersebut terdapat 111 rumah tangga yang dibuang dari daftar disebabkan oleh sudah berubahnya data di lapangan. Dengan demikian terdapat 259 rumah tangga yang tersisa yang menjadi prioritas utama pendataan. Kemudian target pendataan diperluas pada rumah tangga yang dianggap miskin menurut persepsi warga. Terdapat tambahan sebanyak 155 rumah tangga yang menjadi prioritas kedua pendataan. Hasil pendataan menunjukkan terdapat $35.9 \%$ (93 rumah tangga) dari 259 rumah tangga dalam kelompok prioritas pertama yang dikategorikan tidak miskin. Sedangkan pada kelompok prioritas kedua diperoleh hasil terdapat sebanyak $37.4 \%$ (58 rumah tangga) dari 155 rumah tangga yang termasuk kategori tidak miskin. Dengan jumlah rumah tangga di Desa Karangwangi sebanyak 1436, maka dengan rumah tangga miskin hasil pendataan sebanyak 263 artinya terdapat 18,3\% rumah tangga di Desa Karangwangi yang termasuk kategori miskin.
\end{abstract}

Kata Kunci: kemiskinan, keakuratan data, swadaya masyarakat.

\section{PENDAHULUAN}

Secara harfiah, kemiskinan berasal dari kata dasar miskin yang artinya tidak berharta-benda (Ali dkk, 1996). Kemiskinan dalam Kamus Besar Bahasa Indonesia mempunyai persamaan arti dengan kata kefakiran. Dua kata ini biasanya disebutkan secara bersamaan yakni fakir miskin yang berarti orang yang sangat kekurangan. Di dalam kamus lisanu al-Arabi, pengertian kata miskin dibedakan dengan kata faqir. Di sana dijelaskan bahwa kondisi miskin masih lebih baik bila dibandingkan dengan kondisi faqir. Faqir berarti tidak memiliki apapun sedangkan miskin masih memiliki sebagian harta (Mukarram, 1414H).

Beberapa ahli mempunyai pemahaman yang berbeda-beda dalam mendefinisikan kemiskinan. Penggunaan tolok ukur yang berbeda-beda dalam menakar kemiskinan, menghasilkan pengertian yang berbeda pula tentang siapa saja yang pantas dikatakan miskin. Dalam rangka mengentaskan kemiskinan, pemerintah menetapkan suatu standar bahwa yang termasuk golongan miskin adalah mereka yang tidak mampu memenuhi kebutuhan pokok. Dalam konteks keindonesiaan, yang dimaksud dengan kebutuhan pokok adalah beras.

Permasalahan pendataan kemiskinan menjadi kendala hampir di berbagai tempat, hal tersebut akibat dari faktor pendataan yang dilakukan secara parsial, sehingga tidak ada data yang akurat tentang penduduk miskin. Faktor ketidakakuratan data kemiskinan tersebut menyebabkan indikator ketercapaian pengentasan kemiskinan dan ketepatan sasaran program 
di beberapa wilayah tidak berjalan sebagaimana harapan dari masyarakat, sehingga sering menimbulkan konflik di masyarakat saat pembagian bantuan maupun pelaksanaan program.

Berdasarkan identifikasi masalah tersebut, maka kekisruhan mengenai data kemiskinan disebabkan oleh: a. data kemiskinan tidak akurat, b. tidak adanya pemetaan sosial berbasis partisipatif masyarakat, dan c. tidak adanya akses publik terhadap data kemiskinan yang telah dikumpulkan dan diverifikasi. Oleh karena itu maka perlu dilakukan penyusunan data kemiskinan langsung oleh masyarakat dengan pendampingan dari pihak akademisi. Tujuannya yaitu agar tercipta data kemiskinan yang akurat, timbulnya rasa empati dan saling membantu dan ketercapaian pengentasan kemiskinan melalui swadaya masyarakat. Metode yang digunakan adalah pelatihan, pendampingan, dan implementasi.

\section{DATA KEMISKINAN}

Bank dunia menetapkan mereka yang disebut sebagai penduduk miskin adalah mereka yang berpenghasilan kurang dari \$5 per hari (Ridwan, 2012). Jika standar ini ditetapkan di Indonesia maka jumlah penduduk miskin akan sangat banyak. Karena itu, Indonesia mempunyai standar tersendiri dalam menggolongkan kelompok miskin.

Pada awal pemerintahan Orde Baru, data yang dipakai pemerintah, termasuk data keluarga, terpencar di masing-masing departemen sesuai dengan kepentingannya. Sistem dan prosedurnya pun berbeda-beda antara satu departemen dan departemen lainnya sehingga sulit untuk digabungkan menjadi data nasional (Isdijoso dkk, 2016).

Kemudian Badan Koordinasi Keluarga Berencana Nasional (BKKBN) secara khusus mencatat dan melakukan pemantauan keluarga di Indonesia dan hasilnya dikumpulkan dalam satu pangkalan data yang bersifat nasional. Sistem pendataan ini dilakukan secara konsisten dengan pelaporan bulanan dari pusat kesehatan masyarakat (puskesmas) kepada BKKBN Pusat, antara lain, tentang data jumlah pengguna kontrasepsi. Pada 1985 BKKBN mengembangkan sistem pendataannya dan melakukan survei perencanaan keluarga nasional. Pada 1994 BKKBN menambah dua bagian dalam surveinya, yaitu ukuran kesejahteraan keluarga dan karakteristik demografi keluarga. Bagian kesejahteraan keluarga digunakan untuk penargetan keluarga miskin yang dibagi dalam lima kategori kesejahteraan, yaitu keluarga prasejahtera (Pra-KS), keluarga sejahtera 1 (KS1), keluarga sejahtera 2 (KS2), keluarga sejahtera 3 (KS3), dan keluarga sejahtera 3 plus (KS3 Plus).

Pada saat terjadi krisis ekonomi 1997/1998, BKKBN menggolongkan keluarga miskin menjadi Keluarga Prasejahtera Plus (KPS+), yakni keluarga yang memenuhi kriteria KPS ditambah lima kriteria lainnya, yaitu: (i) kepala keluarga terkena pemutusan hubungan kerja (PHK); (ii) anak putus sekolah; (iii) tidak mampu berobat bila sakit; (iv) tidak mampu makan dua kali sehari; dan (v) tidak mampu mengonsumsi lauk-pauk yang berprotein.

Badan Pusat Statistik pada 2005 melakukan pendataan untuk penargetan Program Bantuan Langsung Tunai dengan berpedoman pada Instruksi Presiden Nomor 12 Tahun 2005. Sistem pendataan ini disebut Pendataan Sosial-Ekonomi Penduduk Tahun 2005 (PSE05). Tujuan PSE05 adalah memperoleh daftar nama dan alamat rumah tangga miskin, urutan rumah tangga miskin berdasarkan tingkat keparahannya di kabupaten/kota, dan klasifikasi rumah tangga miskin bila digolongkan menjadi sangat miskin, miskin, dan hampir miskin.

Pendataan dilakukan dalam unit wilayah Satuan Lingkungan Setempat (SLS) sebagai basis wilayah kerja. SLS terkecil di wilayah Indonesia pada umumnya adalah rukun tetangga (RT), atau banjar di Bali, jurong di Sumatra Barat, dan kampung atau dusun di wilayah yang belum menggunakan RT.

Dalam menentukan rumah tangga miskin, BPS menggunakan 14 variabel untuk menentukan apakah suatu rumah tangga layak dikategorikan miskin.

Dalam PSE05, sebuah rumah tangga dikatakan miskin apabila sekurang-kurangnya memenuhi 9 kriteria dari 14 kriteria di bawah ini:

1. Luas lantai bangunan tempat tinggalnya kurang dari $8 \mathrm{~m}^{2}$ per orang;

2. Lantai bangunan tempat tinggalnya terbuat dari tanah/bambu/kayu murahan;

3. Dinding bangunan tempat tinggalnya terbuat dari bambu/rumbia/kayu berkualitas rendah atau tembok tanpa diplester;

4. Air minum berasal dari sumur/mata air yang tidak terlindung/sungai/air hujan; 
5. Tidak memiliki fasilitas buang air besar/bersama-sama rumah tangga lain menggunakan satu jamban;

6. Sumber penerangan rumah tangga tidak menggunakan listrik;

7. Tidak memiliki tabungan/barang yang mudah dijual dengan nilai minimal Rp500.000 seperti sepeda motor (kredit/nonkredit), emas, hewan ternak, kapal motor ataupun barang modal lainnya.

8. Sumber penghasilan kepala rumah tangga adalah: petani dengan luas lahan 0,5 ha, buruh tani, nelayan, buruh bangunan, buruh perkebunan, atau pekerjaan lainnya dengan pendapatan di bawah Rp600.000 per bulan;

9. Bahan bakar untuk memasak sehari-hari adalah kayu bakar/arang/minyak tanah;

10. Hanya mengonsumsi daging/susu/ayam satu kali dalam seminggu;

11. Hanya membeli satu stel pakaian baru dalam setahun;

12. Hanya mampu makan satu/dua kali dalam sehari;

13. Tidak sanggup membayar biaya pengobatan di puskesmas/poliklinik; dan

14. Pendidikan terakhir kepala rumah tangga: tidak sekolah/tidak tamat sekolah dasar (SD)/hanya SD.

\section{HASIL DAN PEMBAHASAN}

Kabupaten Subang pada tahun 2016 memiliki angka keluarga prasejahtera sebesar 12\%. Angka ini berada sedikit di atas angka nasional yang sebesar 11,22\%. Berbagai permasalahan dimungkinkan menjadi kendala, seperti data base yang tidak akurat serta egosektor tiap-tiap Satuan Kerja Perangkat Daerah (SKPD), dan kurang koordinasi antar anggota Tim Koordinasi Penanggulangan Kemiskinan Daerah (TKPKD).

Sebanyak 56.877 dari 468.764 keluarga di Kabupaten Subang hidup dalam kategori prasejahtera. Data kemiskinan yang diambil oleh BPS Kabupaten Subang selama ini adalah berdasarkan data sampel-sampel per blok, tidak dilakukan sensus. Banyak ketidakpuasan dari masyarakat terhadap data ini, sehingga pelaksanaan program tidak tepat sasaran. Ketidaktepatan sasaran disebabkan oleh perbedaan pendapat siapa yang berhak dan yang tidak dalam pemberian program berdasarkan kuota, bukan bersifat kualitatif. (http: / / www.subang.go.id).

Kecamatan Binong berada di wilayah Kabupaten Subang. Letak kecamatan ini berada di jalur utama jalan provinsi Subang - Pamanukan dengan batas-batas sebagai berikut: di bagian utara berbatasan dengan Kecamatan Tambakdahan. Di sebelah selatan berbatasan dengan Kecamatan Pagaden. Di sebelah timur berbatasan dengan Kecamatan Compreng dan Kecamatan Cipunagara. Sedangkan di bagian barat berbatasan dengan Kecamatan Cikaum dan Kecamatan Ciasem seperti yang tersaji dalam Gambar 1. Secara umum luas Kecamatan Binong seluas $50,98 \mathrm{~km}^{2}$, dengan tata guna lahan di dominasi oleh pertanian dengan mata pencaharian masyarakat sebagian besar petani dan buruh tani.

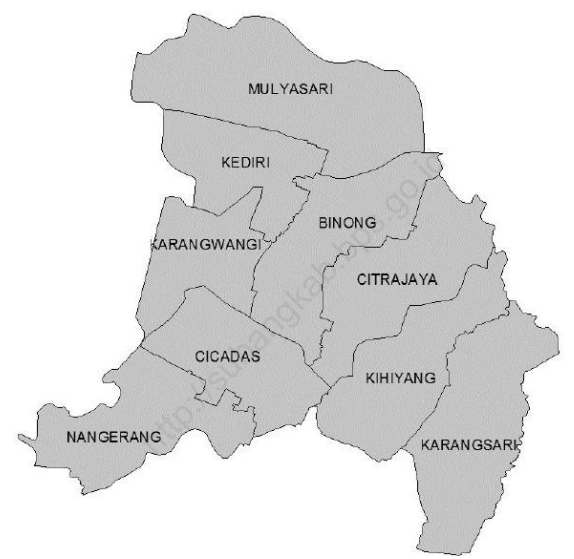

Gambar 1. Peta Kecamatan Binong 
54 Abdul Kudus, dkk.

Salah satu desa di Kecamatan Binong yang cukup maju adalah Desa Karangwangi. Di sini dilakukan verifikasi data kemiskinan langsung oleh masyarakat dengan pendampingan dari akademisi. Masyarakat yang dilibatkan berasal dari kalangan perangkat desa, lembaga desa, RT/RW, Karang Taruna, kader PKK, dan tokoh-tokoh masyarakat

Dengan menggunakan rujukan Daftar Penerima Manfaat (DPM) Beras Sejahtera di Desa Karangwangi yang berisi 370 rumah tangga, maka proses verifikasi data rumah tangga miskin dimulai. Pada tahap awal terdapat 111 rumah tangga yang dibuang dari daftar dikarenakan kondisi rumah tangga tersebut sudah semakin baik, atau karena dirasakan oleh surveyor tidak layak masuk ke dalam daftar. Sehingga tersisa sebanyak 259 rumah tangga di dalam daftar. Pada tahap kedua dilakukan perluasan target pendataan untuk menyasar rumah tangga yang dirasakan miskin oleh surveyor. Hasilnya terdapat tambahan sebanyak 155 rumah tangga. Sehingga total rumah tangga yang didata ada sebanyak 414 rumah tangga sebagaimana tercantum dalam Tabel 1.

Tabel 1. Rekapitulasi pendataan rumah tangga miskin

\begin{tabular}{|l|c|c|c|}
\hline \multicolumn{1}{|c|}{ Data base } & $\begin{array}{c}\text { Jumlah rumah } \\
\text { tangga }\end{array}$ & $\begin{array}{c}\text { Jumlah rumah } \\
\text { tangga terdata }\end{array}$ & $\begin{array}{c}\text { Jumlah rumah } \\
\text { tangga miskin }\end{array}$ \\
\hline \hline DPM Rastra & 370 & 259 & 166 \\
\hline Tambahan & 155 & 155 & 97 \\
\hline \multicolumn{2}{r|}{ Total } & 414 & 263 \\
\hline
\end{tabular}

Keterangan: Total rumah tangga di Desa Karangwangi sebanyak 1436

Hasil pendataan tahap awal terhadap 259 rumah tangga diperoleh hasil bahwa ada 166 rumah tangga yang memenuhi sekurang-kurangya 9 kriteria rumah tangga miskin. Dengan demikian terdapat 93 rumah tangga yang salah sasaran dalam penyaluran beras sejahtera. Karena data awal ini basisnya adalah DPM Beras Sejahtera, maka ini berarti persentase salah sasaran dalam penyaluran beras sejahtera sebesar $35,9 \%$.

Pendataan tahap kedua terhadap 155 rumah tangga di luar DPM Beras sejahtera menunjukkan hasil bahwa 97 diantaranya memenuhi sekurang-kurangya 9 kriteria rumah tangga miskin. Dengan kata lain terdapat ketidaksesuaian sebanyak 58 rumah tangga yang dianggap oleh surveyor sebagai rumah tangga miskin, padahal setelah diperiksa dengan kriteria BPS ternyata bukan rumah tangga miskin. Persentase ketidaksesuaiannya sebesar $37,4 \%$.

Dari gabungan data tahap kesatu dan kedua yang berjumlah sebanyak 414 rumah tangga kemudian dirinci berapa banyak rumah tangga yang memenuhi berbagai kriteria miskin. Tabel 2 menyajikan hasil perincian untuk kriteria kemiskinan berdasarkan luas lantai rumah perkapita. Menurut kriteria ini terdapat 9\% rumah tangga di Desa Karangwangi yang tergolong rumah tangga miskin. Persentasenya kecil mengingat ketersediaan tanah untuk bangunan di daerah pedesaan tidak terlalu menjadi masalah. Di samping itu juga diperoleh hasil bahwa rata-rata luas lantai per orang dari 414 rumah tangga yang terdata adalah seluas $12,3 \mathrm{~m}^{2}$.

Tabel 2. Rekapitulasi rumah tangga berdasarkan kriteria luas lantai

\begin{tabular}{|l|l|l|}
\hline Kriteria Luas Lantai & $\begin{array}{l}\text { Jumlah Sampel Rumah } \\
\text { Tangga }\end{array}$ & $\begin{array}{l}\text { Persentase } \\
\text { Seluruh Terhadap } \\
\text { Rumah Tangga (N=1436) }\end{array}$ \\
\hline \hline$<8 \mathrm{~m}^{2}$ & 125 & $9 \%$ \\
\hline$\geq 8 \mathrm{~m}^{2}$ & 289 & \\
\hline
\end{tabular}

Hasil pemeriksaan terhadap kriteria kedua mengenai jenis lantai disajikan dalam Tabel 3. Menurut kriteria ini terdapat 23\% rumah tangga yang miskin. Hal ini dapat dipahami mengingat lokasi pendataan adalah di daerah pedesaan dimana susah untuk mendapatkan bahan lantai yang lebih baik. Masyarakat lebih cenderung menggunakan bahan yang ada di sekitarnya. 
Tabe1 3. Rekapitulasi rumah tangga berdasarkan kriteria jenis lantai

\begin{tabular}{|l|l|l|}
\hline Kriteria Jenis Lantai & $\begin{array}{l}\text { Jumlah Sampel Rumah } \\
\text { Tangga }\end{array}$ & $\begin{array}{l}\text { Persentase Terhadap } \\
\text { Seluruh Populasi Rumah } \\
\text { Tangga (N=1436) }\end{array}$ \\
\hline \hline Tanah/bambu/kayu murahan & 333 & $23 \%$ \\
\hline Bahan lebih baik & 81 & \\
\hline
\end{tabular}

Menurut kriteria ketiga tentang jenis dinding rumah terdapat 25\% rumah tangga yang tergolong miskin sebagaimana tertera dalam Tabel 4. Sama halnya dengan jenis lantai, maka rumah tangga miskin berdasarkan jenis dinding ini juga persentasenya hampir sama. Hal ini berarti terdapat kecenderungan yang sama antara jenis lantai dengan jenis dinding dari rumah-rumah keluarga miskin di lokasi pendataan.

Tabel 4. Rekapitulasi rumah tangga berdasarkan kriteria jenis dinding

\begin{tabular}{|l|l|l|}
\hline Kriteria Jenis Dinding & $\begin{array}{l}\text { Jumlah Sampel Rumah } \\
\text { Tangga }\end{array}$ & $\begin{array}{l}\text { Persentase Terhadap } \\
\text { Seluruh Populasi Rumah } \\
\text { Tangga (N=1436) }\end{array}$ \\
\hline $\begin{array}{l}\text { Bambu/rumbia/kayu jelek } \\
\text { /tembok tanpa diplester }\end{array}$ & 363 & $25 \%$ \\
\hline Bahan lebih baik & 51 & \\
\hline
\end{tabular}

Perincian dilakukan terhadap kriteria keempat sampai kriteria keempat belas, kemudian juga dilakukan perincian banyaknya kriteria kemiskinan yang dipenuhi oleh rumah tangga yang didata. Tabel 5 menyajikan hasil bahwa mayoritas rumah tangga yang didata memenuhi 10 kriteria kemiskinan, dan tak ada rumah tangga yang memenuhi semua 14 kriteria kemiskinan.

Tabel 5. Rekapitulasi jumlah rumah tangga berdasarkan banyaknya kriteria kemiskinan yang terpenuhi

\begin{tabular}{|l|c|c|}
\hline $\begin{array}{l}\text { Banyaknya Kriteria } \\
\text { yang Terpenuhi }\end{array}$ & $\begin{array}{l}\text { Jumlah Rumah } \\
\text { Tangga }\end{array}$ & $\begin{array}{l}\text { Persentase } \\
\text { Populasi Rumah Tangga (N=1436) }\end{array}$ \\
\hline 1 kriteria miskin & 3 & $0,2 \%$ \\
\hline 2 kriteria miskin & 1 & $0,0 \%$ \\
\hline 3 kriteria miskin & 9 & $0,0 \%$ \\
\hline 4 kriteria miskin & 14 & $0,6 \%$ \\
\hline 5 kriteria miskin & 19 & $1,0 \%$ \\
\hline 6 kriteria miskin & 36 & $1,3 \%$ \\
\hline 7 kriteria miskin & 68 & $2,5 \%$ \\
\hline 8 kriteria miskin & 151 & $4,7 \%$ \\
\hline Sub total 1 sampai 8 & 87 & $10,5 \%$ \\
\hline 9 kriteria miskin & 94 & $6,0 \%$ \\
\hline 10 kriteria miskin & 56 & $6,5 \%$ \\
\hline 11 kriteria miskin & 17 & $3,9 \%$ \\
\hline 12 kriteria miskin & 9 & $1,1 \%$ \\
\hline 13 kriteria miskin & 0 & $0,6 \%$ \\
\hline 14 kriteria miskin & 263 & $0,0 \%$ \\
\hline Sub total 9 sampai $14 *$ & & $18,3 \%$ \\
\hline
\end{tabular}




\section{Abdul Kudus, dkk.}

.Sebagaimana definisi rumah tangga miskin versi BPS bahwa rumah tangga miskin adalah yang sekurang-kurangnya memenuhi 9 kriteria dari 14 kriteria yang ada, maka diperoleh banyaknya rumah tangga yang memenuhi sekurang-kurang 9 kriteria miskin ada sebanyak 263 rumah tangga miskin. Dengan tambahan informasi bahwa di Desa Karangwangi terdapat total sebanyak 1436 keluarga, maka berarti persentase rumah tangga miskin sebesar 18,3\%.

\section{KESIMPULAN}

Verifikasi data kemiskinan secara swadaya berhasil mengidentifikasi rumah tangga yang miskin dengan akurat karena masyarakat sebagai komponen inti dalam suatu lingkungan ikut terlibat. Pihak akademisi melakukan pendampingan selama pendataan sehingga terjadi transfer ilmu kepada masyarakat.

Kondisi Kesejahteraan di Desa Karangwangi masuk dalam kategori kurang baik dengan tingkat kemiskinan sebesar 18,3\%. Dengan diperolehnya data yang lebih akurat, maka akan lebih memudahkan pemerintah daerah setempat untuk melakukan tindakan dalam upaya meningkatkan kesejahteraan masyarakat di masa yang akan datang.

\section{UCAPAN TERIMA KASIH}

Artikel ini disusun berdasarkan kegiatan Pengabdian kepada Masyarakat yang didanai oleh LPPM Universitas Islam Bandung anggaran tahun 2017 dengan Skema P3M.

\section{DAFTAR PUSTAKA}

Ali, Lukman dkk, 1996, Kamus Besar Bahasa Indonesia, Edisi kedua, cetakan ketujuh, Jakarta: Balai Pustaka.

BPS Subang. 2015. Subang Dalam Angka Tahun 2015. ISSN : 0215.4285

Isdijoso, W., Suryahadi, A., dan Akhmadi. 2016. Penetapan Kriteria dan Variabel Pendataan Penduduk Miskin yang Komprehensif dalam Rangka Perlindungan Penduduk Miskin di Kabupaten/Kota. The SMERU Research Institute

Muhammad bin Mukarram bin 'ali. 1414 H. Lisan al-'Arabi, Vol. 5, (Beirut: Dar Sadir.

Ridwan, Muhtadi. 2012. Geliat Ekonomi Islam: Memangkas Kemiskinan, menodorong perubahan. Malang: UIN Maliki Press 